\title{
Avanços no conhecimento do processamento da fluência em leitura: da palavra ao texto
}

\author{
Improvements in the knowledge of the reading fluency \\ processing: from word to text
}

\author{
Ana Luiza Gomes Pinto Navas ${ }^{1}$, Joana Cecilia Baptista Ramalho Pinto ${ }^{2}$, Paula Roberta Rocha Dellisa ${ }^{3}$
}

\begin{abstract}
RESUMO
Os avanços em psicolinguística e nos estudos em neurociências têm contribuído para o maior entendimento dos processos relevantes envolvidos para uma leitura eficiente, mas nem sempre o profissional clínico tem acesso a essa informação de forma sistematizada. Tanto o desenvolvimento de leitura, como a avaliação e a intervenção têm sido largamente influenciados por evidências científicas em um movimento de aproximação cada vez mais necessário entre a teoria e a prática fonoaudiológica. Sendo assim, o objetivo deste trabalho foi reunir informações relevantes para o entendimento do processamento de leitura, sobretudo em relação à importância do desenvolvimento de sua fluência, por meio de uma revisão crítica da literatura nesta área.
\end{abstract}

Descritores: Leitura; Compreensão; Escrita; Processos mentais

\section{INTRODUÇÃO}

A competência em leitura influencia o desempenho de linguagem oral e a elaboração escrita, enriquece o vocabulário, aumenta o nível de informação e conhecimentos gerais, desenvolve o senso crítico, desperta a curiosidade, a sensibilidade e o raciocínio. Todas essas vantagens são suficientes para que haja um maior esforço em fazer dos educandos leitores críticos $\mathrm{e}$, consequentemente, a tornarem-se, cada vez mais, eficientes usuários da língua em seus aspectos oral e escrito ${ }^{(1)}$. Em um âmbito mais restrito, a leitura diz respeito à sua vinculação à alfabetização, à aprendizagem formal do ler e escrever. No sentido amplo, vincula-se à idéia de atribuição de sentido; como concepção, a leitura integra a noção de ideologia, uma maneira de ver o mundo.

Trabalho realizado no Curso de Especialização em Linguagem do Curso de Fonoaudiologia da Faculdade de Ciências Médicas da Santa Casa de São Paulo - FCMSCSP - São Paulo (SP), Brasil.

(1) Doutora, Professora Adjunto do Curso de Fonoaudiologia da Faculdade de Ciências Médicas da Santa Casa de São Paulo - FCMSCSP - São Paulo (SP), Brasil.

(2) Colaboradora do Centro de Estudos de Aprendizagem e Leitura-Escrita do Curso de Fonoaudiologia da da Faculdade de Ciências Médicas da Santa Casa de São Paulo - FCMSCSP - São Paulo (SP), Brasil.

(3) Pós-graduanda (Mestrado) em Saúde, Interdisciplinaridade e Reabilitação pelo Programa de Pós-graduação Stricto Senso da Faculdade de Ciências Médicas da Universidade Estadual de Campinas - UNICAMP - Campinas (SP), Brasil.

Endereço para correspondência: Ana Luiza Gomes Pinto Navas. R. Dr. Cesário Motta Jr, 61, Santa Cecília, São Paulo (SP), Brasil, CEP: 01221-020. E-mail: analunavas@gmail.com

Recebido em: 15/6/2009; Aceito em: 30/9/2009
Nesta linha, o processamento de leitura é uma atividade fundamental na vida cotidiana das pessoas de nossa sociedade moderna. Ler torna possível ao homem construir seu próprio conhecimento, na medida em que proporciona o acesso a todo acervo de conhecimentos acumulado pela humanidade por meio da escrita. É um processo complexo e por intermédio dele é permitido que sejam extraídas informações gráficas de um enunciado, de forma a compreendê-lo e a reconstruir seu significado.

Crianças que se encontram nos estágios iniciais de aquisição de leitura decifram o texto de uma maneira lenta e não-automática, ignorando as marcas de pontuação e se expressando de modo monótono, com pouca variação da prosódia. Porém, com o desenvolvimento das habilidades de leitura, a maioria delas ultrapassa esse estágio e sua leitura torna-se mais fluente, a não ser nos casos de crianças que apresentam dificuldades de leitura, nas quais o alcance dessa fluência é mais difícil ${ }^{(2)}$.

Apenas recentemente a fluência de leitura tem sido objeto de preocupação da escola e, especificamente, da clinica fonoaudiológica, devido à sua relação com a compreensão ${ }^{(3)}$. À medida que a percepção das sequências de letras se torna mais automática, a atenção aos processos primários de decodificação visual diminui, permitindo que a atenção seja realocada para outros aspectos do processamento de leitura, como a semântica $^{(4)}$. Esta é uma dimensão vital da leitura, sendo, portanto, a fluência de leitura necessária para a formação de um leitor de sucesso ${ }^{(5)}$.

Dessa forma, o objetivo deste trabalho foi reunir informações relevantes para o entendimento do processamento da fluência de leitura por meio de uma revisão crítica da literatura 
nesta área. Os temas abordados foram organizados em sessões para facilitar a compreensão.

Para a realização desta pesquisa foram selecionados apenas materiais sobre o desenvolvimento de leitura e fluência de leitura, publicados nos últimos 35 anos. Foram consultados artigos científicos, encontrados em diferentes periódicos nas bases de dados: Science Direct, Sage Journals, Ingenta Connect, Periódicos Capes, LILACS e SciELO, com busca baseada nos descritores fluência de leitura e reading fluency, todos disponíveis na íntegra. Os periódicos consultados datam desde 1974 até março de 2009.

\section{REVISÃO DE LITERATURA}

\section{O desenvolvimento da leitura}

O interesse pelo papel da leitura no desempenho acadêmico foi suscitado pela constatação da difusão entre os educadores de "pseudoverdades", as quais serviram para que se formulassem questões a investigar. Por exemplo, há uma assertiva comum entre os docentes de existir, por parte dos alunos, certa resistência em praticarem a leitura, quer por dever escolar, quer por espontânea atividade cultural ou por lazer ${ }^{(6)}$. Assim como também, muitas vezes, essa resistência à leitura pode provir de uma dificuldade anterior, como na decodificação um texto e, sem auxílio profissional, acabam por criar uma barreira das letras ${ }^{(7)}$.

Atualmente, percebe-se que a leitura é uma das principais deficiências do estudante brasileiro. Dados publicados pelo Instituto Nacional de Estudos e Pesquisas Educacionais - INEP (2004) apontam que 55\% dos alunos cursando a quarta série do Ensino Fundamental apresentaram desempenho crítico ou muito crítico em Língua Portuguesa ${ }^{(8)}$.

Esse fenômeno não acontece apenas no Brasil. Em um panorama internacional, na Bélgica, de 15 a $20 \%$ das crianças do Ensino Fundamental apresentam dificuldades importantes na aquisição da competência de leitura ${ }^{(9)}$. Em um estudo realizado com 146 crianças e adolescentes norte-americanos entre sete e 18 anos de idade que, dentre outras variáveis, registrou diversas medidas de habilidade de leitura e escrita, foi encontrado que metade dos participantes $(\mathrm{N}=71)$ apresentou dificuldades de leitura ${ }^{(10)}$.

A leitura pode ser estudada sob vários aspectos: sóciocultural, afetivo, pedagógico e cognitivo ${ }^{(11)}$. Muitos estudos têm sido feitos sobre a aquisição e o desenvolvimento da leitura ${ }^{(12)}$.

Independentemente da complexidade da estrutura fonológica, o fato do alfabeto representar o idioma oral é poderoso, pois os leitores dos sistemas alfabéticos são capazes de ler palavras nunca vistas antes sem ter que memorizar padrões simbólicos correspondentes a elas. Isso não significa que a escrita alfabética seja aprendida com mais facilidade do que outros sistemas de escrita, mas sim que o processo de associação fonema-grafema, o qual exige o desenvolvimento de capacidades de análise e síntese de fonemas, é apenas uma das condições para se aprender a ler e escrever. O grau de dificuldade também dependerá da transparência da ortografia de cada língua que utiliza a escrita alfabética, sendo que quanto maior for a semelhança entre a quantidade de grafemas e fonemas, maior será a transparência da ortografia, de forma que ela refletirá de modo fidedigno a superfície fonológica da língua em questão, caracterizando uma ortografia rasa ou transparente; ou ao contrário, quando o número de grafemas for consideravelmente maior do que o número de fonemas, a ortografia será profunda, tornando a associação fonemagrafema mais complexa ${ }^{(13)}$.

No aprendizado da leitura, para atingir um ponto chave na compreensão do princípio alfabético da escrita é necessária a descoberta do fonema. $\mathrm{O}$ sujeito necessita adquirir e desenvolver a consciência fonológica, a qual consiste em uma habilidade metalinguística que possibilita o acesso consciente ao nível fonológico da fala e a manipulação cognitiva das representações neste nível, que tanto é necessária para a aprendizagem da leitura e da escrita ${ }^{(13-14)}$.

Ainda não se sabe como a familiaridade com o item escrito depende de conhecimento prévio e da profundidade que esse conhecimento deve ter para influenciar o desempenho tanto na leitura como na escrita ${ }^{(15)}$.

Dessa forma, aprender a ler envolve a integração de um sistema para o processamento da linguagem escrita com outro já existente, o sistema para o processamento da linguagem falada $^{(4)}$.

Em uma perspectiva discursiva, a leitura pode ser vista como um processo de interlocução, delineada pela atividade discursiva, que constitui as interações sociais. Toda palavra é dialógica e todo discurso é tecido pelo discurso do outro, sendo, dessa forma, o dialogismo uma condição constitutiva do sentido. Assim, na leitura, o indivíduo que lê não está somente decodificando e compreendendo a mensagem pronta, e sim participando de uma atividade discursiva, na qual a leitura se constitui um diálogo entre o que se lê e o sujeito que realiza a leitura, buscando, então, a construção do sentido da mensagem ${ }^{(16)}$.

\section{Processamento da linguagem escrita}

A leitura consiste de dois componentes: a decodificação e a compreensão. A decodificação se refere aos processos de reconhecimento da palavra escrita, enquanto que a compreensão é definida como o processo pelo qual as palavras, sentenças ou textos são interpretados ${ }^{(17)}$.

De acordo com uma proposição acerca da descrição do processamento da linguagem escrita, baseada em um modelo conexionista $^{(18-19)}$, são descritos quatro processadores interligados, sendo eles o processador fonológico, o ortográfico, o semântico e o contextual. Neste modelo, os padrões de comportamento são arquivados pelo ajuste das conexões entre as redes de unidades simples de processamento, baseado no feedback sobre a adequação da resposta das unidades de processamento $^{(13)}$.

Neste modelo, o processador fonológico e o ortográfico recebem informações do meio externo, dadas por meio da fala e, por vontade própria do leitor pode ativá-lo, utilizando a subvocalização para facilitar a decodificação das palavras ${ }^{(13)}$. O processador fonológico possui duas grandes funções no processamento da leitura - a de prover um sistema alfabético de suporte, indispensável à manutenção da velocidade e a pre- 
cisão do reconhecimento da palavra necessária para a leitura produtiva; e a de promover um meio de expandir a memória durante a leitura, para as palavras individualmente, o que é essencial para a compreensão do texto ${ }^{(18)}$.

Ainda, é possível dizer que, na realização de atividades como leitura de palavras isoladas ou texto, é necessário um processamento visual refinado dos sinais gráficos para que ocorra a realização de varredura textual na identificação das partes constituintes da palavra. Consequentemente, sua fixação, codificação e, em seguida, compreensão ocorrerão de forma que tal habilidade é requisitada assim que a criança inicia a alfabetização. No entanto, deve-se levar em consideração que, relacionado a este processamento visual, encontra-se o processamento linguístico da leitura, o qual realiza a identificação da palavra mediante o processo de decodificação fonológica, sendo este auxiliado pelo processamento auditivo e, dessa forma, tal processo permite a conversão dos sinais gráficos em representações fonológicas ${ }^{(20)}$.

\section{Fluência de leitura}

Uma leitura disfluente é comumente descrita como uma leitura que se encontra nos estágios iniciais de aquisição, com a decodificação do texto de forma lenta e não-automática, ignorando as marcas de pontuação e exibindo uma expressão monótona, ou seja, sem prosódia ${ }^{(2)}$.

Crianças em séries iniciais tendem a ler de forma mais lenta, uma vez que o processamento se dá pela rota fonológica de conversão grafema-fonema. Contudo, à medida que elas vão se tornando decodificadoras fluentes e lendo a velocidades cada vez maiores, elas passam a ler mais e acabam se familiarizando com a forma visual geral das palavras que tendem a encontrar mais frequentemente. Ou seja, a familiaridade com as palavras acaba por constituir progressivamente um léxico ortográfico que contém a representação ortográfica das palavras mais familiares e lhes permite passar a fazer o reconhecimento visual direto dessas palavras, sem a necessidade de decodificação grafofonêmica para a construção da pronúncia e o acesso ao significado $^{(21-22)}$.

Não há um consenso sobre a definição do termo fluência de leitura, nem quanto a sua relação com a automacidade, velocidade de processamento, taxa de leitura e taxa de reconhecimento de palavra ${ }^{(2,23)}$. Porém, as definições atuais podem ser divididas em três posições: a de que a fluência de leitura é o resultado da qualidade da leitura oral de palavras isoladas e no texto, o que pode ser medido por meio da precisão, prosódia e taxa de leitura; a outra posição assume que a leitura é composta por componentes linguísticos, sendo a fluência o resultado do desenvolvimento da precisão e da automaticidade em cada componente; a última posição, de sistema de análises, vê a fluência de leitura como o resultado da efetividade de diversos sistemas biológicos e cognitivos, apresentando a velocidade de processamento ${ }^{(2)}$.

A fluência na leitura é primeiramente baseada na taxa de decodificação de palavras isoladas ${ }^{(24)}$. Esta, por sua vez, é um resultado da velocidade de processamento dos sistemas cerebrais que são ativados na leitura de palavras. Assim, cada um desses sistemas processa a informação em uma velocidade diferente e, consequentemente, a sincronização da informação que chega de diferentes sistemas é um pré-requisito essencial para a decodificação das palavras.

Segundo a teoria do processamento da informação automática $^{(4)}$, o aprendizado da leitura envolve o aumento da automaticidade no processamento da associação fonema-grafema, transformando essas unidades em palavras reconhecidas e relacionando as palavras, enquanto a leitura é realizada. Assim, a melhora no processamento das letras, das palavras e do texto faz com que o leitor reflita sobre o significado.

Ainda, em relação à definição de fluência na leitura, esta é a habilidade de ler textos em voz alta com velocidade, precisão e prosódia adequada, sendo um fator importante no desenvolvimento da leitura, que representa uma relação direta com a habilidade de reconhecimento automático de palavras que dão apoio na leitura silenciosa ${ }^{(25)}$. Completando essa idéia, uma leitura eficiente é composta por uma fluência, alcançada por meio de um bom desenvolvimento das representações fonológicas das palavras, além da capacidade do sujeito de processá-las de forma rápida, utilizando o mínimo de recursos cognitivos na decodificação, voltando a sua atenção, em maior parte, à compreensão ${ }^{(2)}$.

Ultimamente tem sido verificada grande relação entre fluência de leitura, decodificação e compreensão, de forma que a fluência de leitura oral e o bom desenvolvimento da consciência fonológica têm sido fatores fundamentais na boa proficiência de leitores ${ }^{(26)}$.

Em estudo com crianças com e sem dificuldade de aprendizagem, encontrou-se que a velocidade de acesso ao léxico mental está diretamente relacionada com a habilidade de consciência fonológica e de leitura e escrita ${ }^{(27)}$. A relação entre a fluência de leitura e a compreensão, por meio da teoria da eficiência verbal, revela que o processamento lento da palavra interfere na automaticidade da leitura e, consequentemente, na compreensão ${ }^{(28)}$. No entanto, o autor refere que a leitura lentificada de palavras também é debilitada porque ela consome a memória de trabalho e, portanto, impede que o sujeito reflita sobre o texto enquanto realiza a leitura. Assim, o leitor que possui fluência tem maior tendência a obter melhor habilidade de compreensão ${ }^{(28)}$.

Em outro estudo, com crianças de terceira e quarta séries, encontrou-se que o conhecimento de vocabulário oral, velocidade ortográfica, leitura de pseudopalavras e nomeação rápida foram fatores significantes para predizer a fluência nas séries estudadas $^{(29)}$.

As formas para promover a fluência de leitura oral em crianças têm sido divididas em duas categorias - as que envolvem algum tipo de instrução na forma de modelamento ou apresentação da forma correta; e as que englobam algum meio de leitura rápida e precisa. Outro meio é realizar uma primeira leitura do texto ou ouvir o texto a ser lido. As leituras repetidas têm se mostrado como medida eficiente para promover a fluência, de tal forma que aumentam a precisão e a fluência e promovem melhor compreensão na leitura ${ }^{(26)}$.

\section{Taxa de leitura}

A taxa de leitura é um fator crucial na determinação da 
fluência de leitura, sendo que ela costuma ser vista como um resultado das habilidades eficientes de decodificação e compreensão ${ }^{(30)}$.

Por definição, uma taxa de leitura reduzida pode significar que o sujeito lê menos texto durante o mesmo período de tempo que leitores mais fluentes e assim, terá processado menos texto para lembrar e compreender. Da mesma forma, taxas de leitura menores sugerem que o sujeito esteja despendendo um maior esforço cognitivo em identificar as palavras individualmente, ao contrário de leitores fluentes, que lêem com automaticidade, que dispendem maior esforço cognitivo na compreensão da mensagem $^{(4,30)}$.

A visão básica entre os pesquisadores aponta a taxa de leitura como um fator dependente, visto que a leitura é um processo linguístico. Assim, a sua efetividade é baseada no nível da aquisição, manejo e desempenho dos seus componentes sublexicais, que são: letras, grafemas e fonemas, sílabas, palavras isoladas, pseudopalavras e palavras no texto ${ }^{(2)}$.

A aceleração individual da taxa de leitura tem sido apontada como um fator que promove a melhora na efetividade da leitura, sendo que dados atuais apontam que os benefícios da aceleração da taxa de leitura são, pelo menos, parcialmente atribuídos aos sujeitos que possuem menor vulnerabilidade à distração visual em leitores normais ${ }^{(31)}$.

Vários estudos que investigaram crianças com dificuldades de leitura encontraram grande aumento da taxa de leitura com a aceleração no treinamento da mesma. Segundo os autores, ao se treinar a aceleração, ocorre uma atenção maior na leitura e na velocidade com que se realiza a atividade ${ }^{(31-32)}$.

Embora o desenvolvimento da precisão no reconhecimento da palavra seja um fator importante na leitura, não é a única habilidade determinante para a fluência da mesma ${ }^{(23)}$. Sem a fluência, a compreensão pode não ser alcançada e, então, para se tornar um leitor proficiente, o sujeito necessita de boa representação fonológica das palavras, assim como habilidade de processamento rápido das mesmas. Dessa forma, os leitores que tiverem alcançado a automaticidade nos processos de decodificação podem dedicar maior atenção aos recursos de compreensão e expressão da mensagem ${ }^{(2)}$.

Assim, pode-se afirmar que uma decodificação efetiva é um pré-requisito para a compreensão na leitura e esta efetividade é determinada por meio da automaticidade, que envolve a velocidade, a falta de esforço na decodificação e autonomia ${ }^{(23)}$.

Alguns modelos de aquisição de leitura e de automaticidade reconhecem que a leitura de palavras envolve uma interação entre os sistemas ortográfico, fonológico e semântico ${ }^{(33)}$. Assim, o reconhecimento automático e sem esforço de letras e palavras torna-se um fator crítico no desenvolvimento da fluência de leitura; quando o sujeito adquire uma consciência fonológica e sabe o nome das letras, vai se tornando apto a acessar essas informações de modo rápido, dedicando maior atenção às sequências de letras, o que o ajuda a construir um padrão ortográfico. Quando este padrão é associado com o som, a relação fonológico-ortográfica é estabelecida, permitindo que o sujeito reconheça e relembre essa construção no futuro. Além disso, o processamento rápido em cada nível de leitura leva ao progresso do reconhecimento rápido da palavra ${ }^{(2)}$.
A velocidade de nomeação e automatização de estímulos apresentados, juntamente com a capacidade de acesso lexical, discriminação visual, frequência de uso dos estímulos e competição para a apresentação no menor tempo possível para a nomeação dos códigos, são fatores necessários para o estabelecimento do mecanismo de conversão fonema-grafema, exigido na realização da leitura e escrita de um sistema de escrita com base alfabética, como o Português ${ }^{(27)}$. Dessa forma, a habilidade de leitura pode ser medida por meio da precisão e da automaticidade, pois de acordo com a sua teoria, a fluência de leitura é somente alcançada quando todos os níveis de decodificação do visual ao semântico trabalham automaticamente, de forma que a atenção fique livre para a produção do significado ${ }^{(4)}$.

\section{A prosódia na leitura}

A compreensão da intenção comunicativa está na detecção da estrutura sintática, da escolha lexical e da variação de prosódia em uma língua. Os aspectos prosódicos ou suprasegmentais no discurso se dão por meio de: intensidade, ênfase, velocidade, padrão do ritmo frasal e tempo e, assim, a prosódia tem grande importância semântico-pragmática, desempenhando a função de organizar as mensagens verbais, transformando o input auditivo em padrões estruturais que organizam e mantêm a informação na memória de trabalho ${ }^{(34)}$.

Assim, os sujeitos, tanto na posição de falante, quanto na posição de ouvinte, utilizam a prosódia para facilitar a grande variedade de processamento da informação, incluindo marcação e decodificação do significado lexical, notando as ambiguidades de conteúdo emocional e compreendendo a nova informação. Hierarquicamente, a estrutura da língua incorpora informações fonológicas, morfológicas, sintáticas e semânticas. As informações adicionais não-linguísticas, como características físicas da mensagem e conhecimento metalinguístico, também contribuem para o ato comunicativo e a prosódia é um dos contribuintes para esse processo ${ }^{(2)}$.

O padrão prosódico é uma dimensão da fala que reflete e transfere diferentes tipos de informações ${ }^{(2)}$. A prosódia é compreendida pela métrica, entonação e inflexão, e constitui um padrão organizado que promove informações adicionais à sentença. Dessa forma, a leitura fluente é caracterizada pelo aparecimento de elementos prosódicos como entonação, ênfase e duração ${ }^{(35)}$.

Em relação à compreensão, seu objetivo é construir representações mentais coerentes e a aplicação da prosódia de forma correta é um dos componentes na fluência de leitura que serve como indicador da compreensão do texto. A leitura em voz alta de modo fluente se dá por meio da marcação da prosódia apropriada, com coerência, realização de pausas nos momentos apropriados, assim como a utilização ascendente e descendente da entonação de forma correta, com poucas hesitações; com esses fatores, há uma colaboração para a rápida interpretação do texto lido ${ }^{(34)}$.

Foram identificadas seis marcas de prosódia na leitura: a presença ou ausência de pausas, a extensão das frases entre as pausas, o número de frases apropriadas e inapropriadas, a duração de palavras finais nas frases, a mudança da entonação nas pontuações finais e a ênfase ${ }^{(35)}$. Os leitores capazes de usar 
essas marcas apropriadamente são capazes de transferir o seu conhecimento da sintaxe da fala para o texto.

A leitura oral, assim como a fala, é baseada no processamento linguístico da informação e, assim, a prosódia na leitura, da mesma forma que a prosódia na fala, é produzida com base na representação estrutural que precede o processamento lexical e semântico completo ${ }^{(2)}$.

\section{A compreensão de leitura}

A leitura não envolve apenas o reconhecimento de palavras isoladas. Seu objetivo principal é a compreensão do material lido. Portanto, a identificação de palavras é uma condição necessária, porém não suficiente. A compreensão da leitura requer capacidades cognitivas, como a elaboração de inferências, e linguísticas, como conhecimento do vocabulário, da sintaxe, dentre outras ${ }^{(9)}$.

A literatura sugere uma relação entre automatismo (precisão e rapidez) no reconhecimento de palavras e compreensão de leitura ${ }^{(36)}$. Além do automatismo na identificação de palavras, para compreender um texto é necessário empregar conhecimentos e estratégias que vão além da mera combinação de significados lexicais individuais, sendo necessário elaborar uma representação mental do conteúdo proposicional das mensagens. Proposições são unidades abstratas de significado e implicam, no mínimo, a predicação de algo (uma propriedade, ação, relação etc) acerca de algo (um objeto, argumento etc) ${ }^{(37)}$.

Em síntese, a compreensão textual inclui vários processos cognitivos interrelacionados. Entre eles, os processos básicos de leitura, como o reconhecimento e extração do significado das palavras impressas, são requisitos necessários, mas não suficientes. Uma compreensão textual bem sucedida exige processos cognitivos de alto nível, como capacidade de realizar inferências, habilidades linguísticas gerais, habilidades de memória, conhecimento de mundo, que juntos contribuem para a construção de uma representação macroestrutural do texto $^{(11)}$. Em estudo com crianças pequenas foi identificada uma forte relação entre a fluência de leitura e a compreensão $0^{(14)}$.

Já as crianças mais velhas podem fazer mais inferências que as mais novas em uma tarefa de compreensão de texto longo, porque estrategicamente recuperam informações anteriores a fim de dar maior sentido ao input geral. Diferentemente, as crianças mais novas podem combinar os conteúdos dos componentes apenas quando o segundo destes componentes ocorre para "evocar" o primeiro da memória a longo prazo, ou quando os dois estão temporariamente perto e, assim, conjuntamente presentes na memória de trabalho ${ }^{(38)}$.

Segundo o Modelo de Compreensão de Textos, devido às limitações na memória de curto prazo, o processamento de um texto é feito em ciclos, que correspondem, aproximadamente, a uma frase ${ }^{(39)}$. Destes ciclos, uma estrutura mais geral de significado, a macroestrutura, é extraída das proposições do texto original e mantida na memória episódica junto com os itens finais do ciclo. As frases apresentadas no texto são conhecidas como microestruturas. O ciclo seguinte altera as representações dos anteriores na memória episódica, fazendo com que ocorra a construção gradual de um texto base.

A compreensão de leitura textual em crianças foi analisada por alguns autores brasileiros ${ }^{(11)}$. Em um estudo realizado com crianças, envolvendo processos cognitivos, compreensão e tempo de leitura, os resultados sugerem que as habilidades compreensivas e de memória de curto prazo das crianças melhoram com a escolaridade, o que pode também estar relacionado ao progresso no uso de estratégias metacognitivas. Em uma investigação sobre compreensão, realizada com alunos do Ensino Fundamental, encontrou-se que a maioria dos participantes relatou conseguir identificar e perceber momentos em que a compreensão do conteúdo lido não era alcançada. Além disso, embora os alunos tenham mencionado, de modo geral, estratégias de aprendizagem relevantes para a compreensão da leitura, cabe destacar que, não só a frequência das respostas nas categorias de estratégias foi baixa, mas também o repertório de estratégias identificadas pelos participantes não contemplou uma gama mais diversificada de estratégias. Também verficouse que alunos repetentes revelaram um conjunto de estratégias de compreensão de conteúdo durante a leitura mais simples, quando comparados aos não repetentes ${ }^{(40)}$.

\section{DISCUSSÃO}

O objetivo deste trabalho foi reunir informações relevantes para o entendimento do processamento da fluência de leitura por meio de uma revisão crítica da literatura nesta área.

Dessa forma, foi possível perceber que, em relação à automatização da decodificação e à taxa de leitura, esta última é um fator muito importante a ser medido na avaliação de leitura. Um valor alto para a taxa de leitura sugere que o indivíduo leu mais texto que um leitor com dificuldades e, assim, processou mais palavras e frases para lembrar e compreender. Além disso, um leitor fluente dedica menor esforço cognitivo na identificação das palavras individualmente, podendo alocar maior esforço na compreensão da mensagem lida. Nesta mesma linha, pode-se concluir que os leitores que alcançam a automaticidade nos processos de decodificação também podem dedicar maior atenção aos recursos de compreensão e expressão da mensagem ${ }^{(2,4,24,30-32)}$. Outro ponto interessante a ser ressaltado é a questão da aceleração da taxa de leitura, que tem sido apontada cada vez mais como um meio de promover a fluência de leitura em sujeitos com dificuldades nesta habilidade ${ }^{(2,31-32)}$.

A prosódia, também um traço constituinte da fluência de leitura, poderia atualmente estar sendo explorada não só como um pré-requisito desta última, como uma característica que deve ser avaliada para a constatação da competência em leitura, como também pode ser considerada um importante recurso terapêutico. Ao mesmo tempo em que a melhora da taxa de leitura, a automatização da mesma e a compreensão de um texto lido, são consequências de uma evolução na habilidade de leitura, a adequação da variação de prosódia durante a leitura é um indicador de sua competência.

Ainda que haja inúmeros estudos realizados por diferentes autores, em diversos contextos linguísticos, a avaliação da competência em compreensão de leitura é, ainda, um tema polêmico. Há instrumentos de avaliação dos mais diferentes tipos, mas nenhum suficientemente confiável para abranger todos os aspectos que garantem a eficiência da compreensão. 
É de grande importância a realização de novos estudos na área que venham a contribuir para a elaboração de instrumentos de avaliação da compreensão, que facilitem a descrição deste comportamento e direcionem melhor o programa terapêutico.

\section{COMENTÁRIOS FINAIS}

A partir dos estudos revisados, percebe-se que a fluência de leitura depende de elementos essenciais, tais como: taxa de leitura, automatização, prosódia e compreensão. Quando todos esses fatores operam de forma equilibrada, a fluência é atingida. Por depender de diferentes pré-requisitos, cada um dos mesmos deve estar dentro das conformidades, e o desenvolvimento de investigação científica em fluência de leitura deve pautar-se na compreensão de suas particularidades.

Por meio desta revisão de literatura foi possível reunir informações relevantes para contribuir com o entendimento do processamento de leitura, revendo o papel da taxa de leitura, automatização da decodificação, prosódia e compreensão na fluência de leitura.

\begin{abstract}
Advances in neuroscience and psycholinguistic studies have contributed to a better understanding of relevant processes envolved in an efficient reading. Nevertheless, clinic professionals not always have access to this information in a systematic way. Reading development, assessment and intervention have been widely influenced by scientific evidence, bringing together a necessary link between theory and speech-language pathology practice. Therefore, the purpose of the present study was to gather relevant information towards the understanding of reading processing, especially regarding the development of reading fluency, through a critical literary review in this area.
\end{abstract}

Keywords: Reading; Comprehension; Handwriting; Mental processes

\title{
REFERÊNCIAS
}

1. Rolindo JM, Souza FE Leitura/escritura: um processo de construção de sentido. Rev Educ. 2008;11(12):69-84.

2. Breznitz Z. Fluency in reading: synchronization of process. Mahwah (NJ): Lawrence Erlbaum; 2006.

3. Bourassa DC, Levy BA, Dowin S, Casey A. Transfer effects across contextual and linguistic boundaries: evidence from poor readers. J Exp Child Psychol. 1998;71(1):45-61.

4. LaBerge D, Samuels SJ. Toward a theory of automatic information processing in reading. Cogn Psychol. 1974;6(2):293-323.

5. Welsch RG. Increase oral reading fluency. Intervent School \& Clin. 2006;41(3):180-3.

6. Simões JF, Carnielli BL. A importância da leitura para o desempenho escolar dos alunos do ensino fundamental. Rev Educ PUC-Campinas. 2002;(13):51-63.

7. Bloch P. Comunicação oral da criança e do adulto. Rio de Janeiro: Revinter; 2002.

8. Tonelotto JM, Fonseca LC, Tedrus GM, Martins SM, Gibert MA, Antunes TA et al. Avaliação do desempenho escolar e habilidades básicas de leitura em escolares do ensino fundamental. Aval Psicol. 2005;4(1):33-43.

9. Braibant J. A decodificação e a compreensão: dois componentes essenciais da leitura no $2^{\circ}$ ano primário. In: Grégoire J, Piérart B, organizadores. Avaliação dos problemas de leitura: os novos modelos teóricos e suas implicações diagnósticas. Porto Alegre: Artes Médicas; 1997. p.167-87.

10. Cardoso-Martins C, Pennington BF. Qual é a contribuição da nomeação seriada rápida para a habilidade de leitura e escrita?: evidência de crianças e adolescentes com e sem dificuldades de leitura. Psicol Reflex Crit. 2001;14(2):387.

11. Salles JF, Parente MA. Processos cognitivos na leitura de palavras em crianças: relações com compreensão e tempo de leitura. Psicol Reflex Crit. 2002;15(2):321-31.

12. Cardoso-Martins C. A sensibilidade fonológica e a aprendizagem inicial da leitura e da escrita. Cad Pesqui. 1991;76:41-9.

13. Santos MT, Navas AL, organizadores. Distúrbios de leitura e escrita - teoria e prática. Barueri (SP): Manole; 2002; Aquisição e desenvolvimento da linguagem escrita. p. 1-26.
14. Kudo I, Bazan J. Measuring beginner reading skills: an empirical evaluation of alternative instruments and their potential use for policymaking and accountability in Peru [Internet]. Washington: The World Bank; 2009. Policy Research Working Paper, 4812 [cited 2009 20 Aug]. Available: http://www-wds.worldbank.org/external/default/ WDSContentServer/IW3P/IB/2009/01/07/000158349_200901071636 18/Rendered/PDF/WPS4812.pdf

15. Paolucci JF, Ávila CR. Competência ortográfica e metafonológica: influências e correlações na leitura e escrita de escolares da $4^{a}$ série. Rev Soc Bras Fonoaudiol. 2009;14(1):48-55.

16. Voloshinov VN. Marxism and the philosophy of language. London: Harvard University Press; 1986.

17. Gough PB, Tunmer WE. Decoding, reading, and reading disability. Remed Spec Educ. 1986;7(1):6-10.

18. Adams MJ. Beginning to read: thinking and learning about print. Cambridge: The MIT Press; 1991.

19. Seidenberg MS, McClelland JL. A distributed, developmental model of word recognition and naming. Psychol Rev. 1989;96(4):523-68.

20. Capellini AS, Ferreira TL, Salgado CA, Ciasca SM. Desempenho de escolares bons leitores, com dislexia e com transtorno do déficit de atenção e hiperatividade em nomeação rápida automática. Rev Soc Bras Fonoaudiol. 2007;12(2):114-9.

21. Macedo EC, Capovilla FC, Nikaedo CC, Orsati FT, Lukasova K, Capovilla AG. Teleavaliação da habilidade de leitura no ensino infantil fundamental. Psicol Esc Educ. 2005;9(1):37-46.

22. Santos MT, Navas AL. Linguagem escrita: aquisição e desenvolvimento. In: Ferreira LP, Befi-Lopes DM, Limongi SC. Tratado de fonoaudiologia. São Paulo: Rocca; 2004.

23. Wolf M, Katzir-Cohen T. Reading fluency and its intervention. Sci Stud Read. 2001;5(3):211-39.

24. Breznitz Z. Speed of phonological and orthographic processing as factors in dyslexia: Electrophysiological evidence. Genet Soc Gen Psychol Monogr. 2003;129(2):183-206.

25. Francis DJ, Santi KL, Barr C, Fletcher JM, Varisco A, Foorman BR. Form effects on the estimation of students' oral reading fluency using DIBELS. J Sch Psychol. 2008;46(3):315-42. 
26. Eckert TL, Ardoin SP, Daly EJ, Martens BK. Improving oral reading fluency: a brief experimental analysis of combining an antecedent intervention with consequences. J Appl Behav Anal. 2002;35(3):271-81.

27. Capellini AS, Conrado TL. Desempenho de escolares com e sem dificuldades de aprendizagem de ensino particular em habilidade fonológica, nomeação rápida, leitura e escrita. Rev CEFAC. 2009;11(Supl 2):183-93.

28. Perfetti CA. Reading ability. NewYork: Oxford University Press; 1985.

29. Wood DE. Modeling the relationships between cognitive and reading measures in third and fourth grade children. J Psychoed Assess. 2009;27(2):96-112.

30. Mastropieri MA, Leinart A, Scruggs TE. Strategies to increase reading fluency. Intervention in School and Clinic. 1999;34(5):278-83.

31. Breznitz Z. Effects of accelerated reading rate on memory for text among dyslexic readers. J Educ Psychol. 1997;89(2):289-97.

32. Snellings P, van der Leij A, Jong PF, Block H. Enhancing the reading fluency and comprehension of children with reading disabilities in an orthographically transparent language. J Learn Disabil. 2009;42(4):291305 .
33. Bowers PG, Wolf M. Theoretical links among naming speed, precise timing mechanisms and orthographic skill in dyslexia. Read Writ. 1993;5(1):69-85.

34. Ravid D, Mashraki YE. Prosodic reading, reading comprehension and morphological skills in Hebrew-speaking fourth graders. J Res Read. 2007;30(2):140-156.

35. Dowhower SL. Speaking of prosody: Fluency's unattended bedfellow. Theory Pract. 1991;30(3):165-75.

36. Perfetti CA, Hogaboam T. Relationship between single word decoding and reading comprehension skill. J Educ Psychol. 1975;67(4):461-69.

37. Kintsch W. Comprehension: a paradigm for cognition. New York: Cambridge University Press; 1998.

38. Johnson H, Smith LB. Children's inferential abilities in the context of reading to understand. Child Dev. 1981;52(4):1216-23.

39. Kintsch W, van Dijk TA. Toward a model on text comprehension and production. Psychol Rev. 1978;85(5):363-94.

40. Boruchovitch E. Algumas estratégias de compreensão em leitura de alunos do Ensino Fundamental. Psicol Esc Educ. 2001;5(1):19-25. 